\title{
Excitation Force Identification of Multiple Devices in Railway Vehicles Based on Modal Superposition Method and Kalman Filter
}

\section{Jiangxue Chen}

Tongji University https://orcid.org/0000-0003-0635-8524

Jinsong Zhou ( $\square$ jinsong.zhou@tongji.edu.cn )

Tongji University

Dao Gong

Tongji University

\section{Original Article}

Keywords: Railway vehicle, Active device, Excitation force, Modal superposition method, Kalman filter

Posted Date: June 21st, 2021

DOI: https://doi.org/10.21203/rs.3.rs-530645/v1

License: (c) (1) This work is licensed under a Creative Commons Attribution 4.0 International License.

Read Full License 


\section{Title page}

\section{Excitation force identification of multiple devices in railway vehicles based on modal superposition method and Kalman filter}

Jiang-Xue Chen, born in 1994, is currently a PhD candidate at Institute of Rail Transit, Tongji University, China. His research interests include railway vehicle dynamics and excitation parameter identification.

E-mail: chenjiangxue@tongji.edu.cn

Jin-Song Zhou, born in 1969, is currently a professor at Institute of Rail Transit, Tongji University, China. He received his PhD degree from Shanghai Jiaotong Universtiy, China, in 2003. His research interests include railway vehicle dynamics and vehicle vibration control.

E-mail: jinsong.zhou@tongji.edu.cn

Dao Gong, born in 1985, is currently an associate professor at Institute of Rail Transit, Tongji University, China. He received his PhD degree from Tongji Universtiy, China, in 2012. His research interests include railway vehicle dynamics and vehicle vibration control.

E-mail: gongdao@tongji.edu.cn

Corresponding author: Jin-Song Zhou E-mail: jinsong.zhou@tongji.edu.cn 


\title{
Excitation force identification of multiple devices in railway vehicles based on modal superposition method and Kalman filter
}

\author{
Jiang-Xue Chen ${ }^{1}$ • Jin-Song Zhou ${ }^{1}$ - Dao Gong ${ }^{1}$
}

Received June xx, 201x; revised February xx, 201x; accepted March xx, 201x

(C) Chinese Mechanical Engineering Society and Springer-Verlag Berlin Heidelberg 2017

\begin{abstract}
The excitation force identification of multiple devices in railway vehicles is studied. The vertical dynamic coupling model between the flexible car body of high-speed train and the under-chassis active device with excitation itself is established based on the modal superposition method. The excitation force from device is identified based on Kalman filter. A modal order selection method is developed for improving the identification accuracy based on tolerance index. The identification effects of single and multiple active devices including single-frequency steady-state, multi-frequency steady-state, impact, sawtooth wave and square wave excitation forces are analyzed. An error limit range of $5 \%$ is defined to evaluate the identification results. The results show that the method is suitable for the identification of various steady-state and transient-state excitation forces, and the identification results of excitation forces of single and multiple active devices have good accuracy.
\end{abstract}

Keywords: Railway vehicle - Active device - Excitation force • Modal superposition method $\bullet$ Kalman filter

\section{Introduction}

It is needed to measure the excitation force acting on the structure in many situations, such as vibration reduction design, vibration active control, fault diagnosis and so on. The lightweight design of railway vehicle body and the increase of running speed lead to the problems of intensified flexible vibration and reduced ride quality of high-speed train [1-2]. Un-der-chassis active device is an important source of excitations. However, there are few studies that fully addressing the influence of the actual excitation forces from active devices, and the identification of the excitation forces from active devices in real-time under the actual mounting

Jin-Song Zhou

jinsong.zhou@tongji.edu.cn conditions hasn't been studied yet. Therefore, the vibration reduction design for active device often deviates from the expected vibration reduction effect. The active device of railway vehicles is mainly rotary vibration equipment, such as air compressor and cooling fan. The excitation forces of these devices have the characteristics of steady-state harmonics. For example, if the rotation speed of the cooling fan is $1440 \mathrm{r} / \mathrm{min}(24 \mathrm{r} / \mathrm{s})$, the excitation is based on the harmonic excitation of $24 \mathrm{~Hz}$.

In most cases, it is not possible to measure the excitation force using force sensor directly. Therefore, the measured structural response can be used to estimate the excitation force indirectly. As a typical inverse problem, the identification of external excitation force has been the objective of many researches [3-9] for a long time. A common approach is to determine the frequency response function (FRF) matrix and to calculate the excitation force based on the least squares method [10]. In recent years, time-domain methods have attracted attention. Gunawan et al. [11] studied the problem of impact force reconstruction with the quadratic spline function. Liu et al. [12] proposed a method for identifying dynamic loads acting on stochastic structures based on the Gegenbauer polynomial expansion theory. Samagassi et al. [13] achieved the reconstruction of the impact force on the linear elastic structure by the wavelet correlation vector machine method. Kazemi et al. [14] proposed a dynamic load identification method based on time integral of strain. Unfortunately, as the obtained matrix is generally ill-posed, the calculation results are highly sensitive to measurement errors [15] and can easily lead to recognition failure, so regularization operations are required. Yu and Chan [16] established a bridge-vehicle system model

Institute of Rail Transit, Tongji University, Shanghai 201804, China 
in the laboratory for motion force identification. It is found that it is feasible to use the singular value decomposition (SVD) technique to identify the excitation force. This technique can effectively enhance the identification method and improve the identification accuracy over that of the direct pseudo-inverse solution. However, rejecting singular values smaller than a certain threshold leads to some information to be lost and have a significant effect on results. Critical for the rejection of singular values is a suitable threshold [17]. Hansen [18] and Jacquelin et al. [19] solved discrete ill-posed problems via Tikhonov regularization technique. The successful application of the Tikhonov method requires the choice of an optimal regularization parameter. Liu and $\mathrm{Jr}$ [20] determined the optimum regularization parameter by using the L-curve method. Choi et al. [21] compared the performance of ordinary cross validation (OCV), generalized cross validation (GCV) and L-curve method in determining Tikhonov regularization parameter. The L-curve method performs better than OCV or GCV for high noise, particularly in the operational responses, but less well when these noise levels are low. It is therefore crucial to obtain good estimates of the likely noise in the signals before determining the most appropriate regularization technique. Considering the sparsity of impact force, Qiao et al. [22] proposed an enhanced sparse regularization method based on reweighted 11-norm minimization for reducing the peak force error and improving the identification accuracy of impact force.

In the process of external excitation identification, suppressing noise is essential to improving recognition accuracy. Ma [23-24] proposed combining the Kalman filter [25] and recursive least squares method to identify the excitation force. Where, the Kalman filter was used to suppress noise, and the recursive least squares algorithm used the gain, innovation and covariance matrix generated by the Kalman filter to estimate the excitation force. Subsequently, a numerical simulation study of the excitation force identification of nonlinear systems was performed by combining extended Kalman filter and recursive least squares method [26-27]. In order to identify the excitation force of a cantilever beam, Ma [28] established the state equation of beam by finite element method (FEM). However, for large-scale structures, thousands of degrees of freedom would be obtained after the FEM discretization, which makes the computational process of the recognition of the excitation force highly difficult. Above identification methods are mainly aimed at a single device. In this paper, the excitation force identification of multiple devices in railway vehicles is studied. Regarding physical coordinate response as the result of finite order modal coordinate response superposition via the modal superposition method could achieve the purpose of equation order reduction.

This paper aims to identify the excitation force of the active device in railway vehicles. For this purpose, the physical coordinate responses are converted into the modal coordinate responses. The modal superposition method and Kalman filter are combined. Firstly, the vertical dynamic coupling model between the flexible car body of high-speed railway vehicle and the under-chassis active devices is established based on the modal superposition method in Section 2. The excitation force identification method is introduced with Kalman filter in Section 3. Then, a modal order selection method with tolerance as an index is proposed to solve the problem of identification error caused by improper modal order selection in Section 4. Finally, the identification of single and multiple active devices including single-frequency steady-state, multi-frequency steady-state, impact, sawtooth wave and square wave excitation forces under different noise levels are studied in Section 5. This method is efficient to identify the excitation forces from different devices under car body, which is important to the vibration performance and ride quality of high-speed railway.

\section{Dynamic model of flexible car body of rail- way vehicle with active devices based on modal superposition method}

The vertical dynamic coupling model between the flexible car body and the under-chassis active devices of high-speed railway vehicle is built as shown in Figure 1.

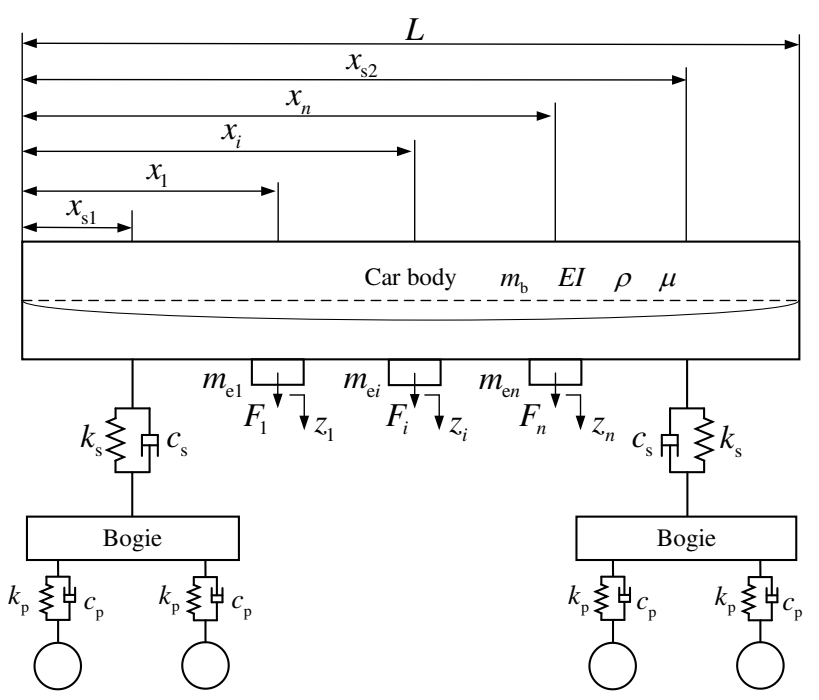

Figure 1 Vertical dynamic coupling model between flexible car body and under-chassis active devices 
In view of the usually low secondary suspension stiffness of high-speed train, the car body is regarded as a homogeneous iso-cross-section Euler-Bernoulli beam with two free ends [29]. To identify the original excitation force of under-chassis active device, the device is rigidly mounted at the chassis of car body directly regardless of the device suspension parameters. Although the device excitation force easily elicits the flexible modal vibration of car body, it can hardly induce the rigid vibration of car body or the vibration of bogie directly. Thus, the influence of bogie vibration is ignored in the model, and the secondary suspension of car body is considered to bear static load only. The railway vehicle is in a static state, and the track excitation is not considered here. Assuming there are a total of $n$ rigid suspension devices, $x_{i}$ is the position coordinates of the $i$-th device, $z_{i}$ is the vertical displacement of car body at the hanging position of the $i$-th device, $F_{i}$ is the excitation force of the $i$-th device, $m_{\mathrm{e} i}$ is the mass of the $i$-th device, $x_{\mathrm{s} 1}$ is the position coordinates of the secondary suspension on the left side, $x_{\mathrm{s} 2}$ is the position coordinates of the secondary suspension on the right side, $k_{\mathrm{s}}$ and $c_{\mathrm{s}}$ are the stiffness and damping parameters of the secondary suspension, respectively, $k_{\mathrm{p}}$ and $c_{\mathrm{p}}$ are the stiffness and damping parameters of the primary suspension, respectively, $m_{\mathrm{b}}$ is the mass of car body, $L$ is the length of car body, $\rho$ is the mass per unit length of car body, $\mu$ is the hysterical damping of car body, and $E I$ is the equivalent bending stiffness of car body section.

Suppose that the vertical displacement [30] of the car body is $z(x, t)$, and $F_{\mathrm{s} 1}, F_{\mathrm{s} 2}$ are the secondary suspension support forces, then the partial differential equation for car body vibration is

$$
\begin{aligned}
& E I \frac{\partial^{4} z(x, t)}{\partial x^{4}}+\mu E I \frac{\partial^{5} z(x, t)}{\partial t \partial x^{4}}+\rho \frac{\partial^{2} z(x, t)}{\partial t^{2}}, \\
& =F_{\mathrm{s} 1}\left(x_{\mathrm{s} 1}, t\right)+F_{\mathrm{s} 2}\left(x_{\mathrm{s} 2}, t\right)+\sum_{i=1}^{n} F_{i}\left(x_{i}, t\right)
\end{aligned}
$$

When only the prior $N$-order flexible modal vibration of car body is considered irrespective of the rigid body vibration, the vertical displacement of the car body can be expressed according to the modal superposition method as

$$
z(x, t)=\sum_{j=1}^{N} Y_{j}(x) q_{j}(t)
$$

where $Y_{j}(x)$ and $q_{j}(t)$ represent the modal shape function and modal coordinates of the $j$-th order flexible vibration of car body, respectively. $\bar{N}$ measuring points of car body displacement can be chosen to write Eq. (2) in a matrix form as

$$
\boldsymbol{Z}_{\bar{N} \times 1}=\boldsymbol{Y}_{\bar{N} \times N} \boldsymbol{Q}_{N \times 1},
$$

The observation problem of the modal coordinates of car body can be calculated by Eq. (4):

$$
\boldsymbol{Q}_{N \times 1}=\left(\boldsymbol{Y}_{\bar{N} \times N}^{\mathrm{T}} \boldsymbol{Y}_{\bar{N} \times N}\right)^{-1} \boldsymbol{Y}_{\bar{N} \times N}^{\mathrm{T}} \boldsymbol{Z}_{\bar{N} \times 1},
$$

If the car body is considered as a free beam, its modal shape function is [30]

$$
Y(x)=\operatorname{ch} k x+\cos k x-\frac{\operatorname{ch} k L-\cos k L}{\operatorname{sh} k L-\sin k L}(\operatorname{sh} k x-\sin k x),
$$

where $\operatorname{ch} k L \cos k L=1$.

By substituting Eq. (2) into Eq. (1), each term is multiplied by $Y_{j}(x)$, and then the integral along the car length is taken, the $j$-th order modal equation of motion for the car body can be obtained by exploiting the orthogonal relationship between the modal shape functions as following:

$$
M_{j} \ddot{q}_{j}(t)+\mu \omega_{j}^{2} M_{j} \dot{q}_{j}(t)+\omega_{j}^{2} M_{j} q_{j}(t)=F_{Y_{j}},
$$

Respecting the left terms of Eq. (6), $M_{j}=\int_{0}^{L} \rho Y_{j}^{2}(x) \mathrm{d} x$ denotes the $j$-th modal mass, $\omega_{j}=k_{j}^{2} \sqrt{E I / \rho}$ denotes the $j$ th modal frequency, $\mu \omega_{j}^{2} M_{j}$ is the $j$-th modal damping, and $\omega_{j}^{2} M_{j}$ the $j$-th modal stiffness. Respecting the right term of Eq. (6), $\quad F_{Y_{j}}=F_{\mathrm{s} 1}\left(x_{\mathrm{s} 1}, t\right) Y_{j}\left(x_{\mathrm{s} 1}\right)+F_{\mathrm{s} 2}\left(x_{\mathrm{s} 2}, t\right) Y_{j}\left(x_{\mathrm{s} 2}\right)+\sum_{i=1}^{n} F_{i}\left(x_{i}, t\right) Y_{j}\left(x_{i}\right)$ denotes the $j$-th modal force.

When the first $N$-order modes of the car body are considered, the matrix form of system dynamics equation is

$$
M \ddot{q}+C \dot{q}+K q=F,
$$

where

$$
\boldsymbol{q}=\left[\begin{array}{llll}
q_{1} & q_{2} & \cdots & q_{N}
\end{array}\right]^{\mathrm{T}},
$$

$\boldsymbol{M}=\left[\begin{array}{llll}M_{1} & & & \\ & M_{2} & & \\ & & \ddots & \\ & & & M_{N}\end{array}\right]$, 
$\boldsymbol{C}=\left[\begin{array}{llll}\mu \omega_{1}^{2} M_{1} & & & \\ & \mu \omega_{2}^{2} M_{2} & & \\ & & \ddots & \\ & & & \mu \omega_{N}^{2} M_{N}\end{array}\right]$,

$\boldsymbol{K}=\left[\begin{array}{llll}\omega_{1}^{2} M_{1} & & & \\ & \omega_{2}^{2} M_{2} & & \\ & & \ddots & \\ & & & \omega_{N}^{2} M_{N}\end{array}\right]$,

$\boldsymbol{F}=\left[\begin{array}{c}F_{\mathrm{s} 1}\left(x_{\mathrm{s} 1}, t\right) Y_{1}\left(x_{\mathrm{s} 1}\right)+F_{\mathrm{s} 2}\left(x_{\mathrm{s} 2}, t\right) Y_{1}\left(x_{\mathrm{s} 2}\right)+\sum_{i=1}^{n} F_{i}\left(x_{i}, t\right) Y_{1}\left(x_{i}\right) \\ F_{\mathrm{s} 1}\left(x_{\mathrm{s} 1}, t\right) Y_{2}\left(x_{\mathrm{s} 1}\right)+F_{\mathrm{s} 2}\left(x_{\mathrm{s} 2}, t\right) Y_{2}\left(x_{\mathrm{s} 2}\right)+\sum_{i=1}^{n} F_{i}\left(x_{i}, t\right) Y_{2}\left(x_{i}\right) \\ \vdots \\ F_{\mathrm{s} 1}\left(x_{\mathrm{s} 1}, t\right) Y_{N}\left(x_{\mathrm{s} 1}\right)+F_{\mathrm{s} 2}\left(x_{\mathrm{s} 2}, t\right) Y_{N}\left(x_{\mathrm{s} 2}\right)+\sum_{i=1}^{n} F_{i}\left(x_{i}, t\right) Y_{N}\left(x_{i}\right)\end{array}\right]$.

By defining the state variable $\boldsymbol{X}=\left[\begin{array}{ll}\boldsymbol{q} & \dot{\boldsymbol{q}}\end{array}\right]^{\mathrm{T}}$ and taking the modal coordinates of car body as the observation target, the continuous time state-space equation and observation equation of the system can be written separately as

$$
\begin{gathered}
\dot{\boldsymbol{X}}(t)=\boldsymbol{A} \boldsymbol{X}(t)+\boldsymbol{B} \boldsymbol{F}(t), \\
\boldsymbol{Z}(t)=\boldsymbol{H} \boldsymbol{X}(t),
\end{gathered}
$$

where

$$
\begin{aligned}
\boldsymbol{A} & =\left[\begin{array}{cccc}
0 & \multicolumn{1}{c}{} \\
-\boldsymbol{M}^{-1} \boldsymbol{K} & -\boldsymbol{M}^{-1} \boldsymbol{C}
\end{array}\right], \boldsymbol{B}=\left[\begin{array}{c}
0 \\
-\boldsymbol{M}^{-1}
\end{array}\right], \\
\boldsymbol{H} & =\left[\begin{array}{cccccccc}
1 & 0 & \cdots & 0 & 0 & 0 & \cdots & 0 \\
0 & 1 & \cdots & 0 & 0 & 0 & \cdots & 0 \\
\vdots & \vdots & \ddots & \vdots & \vdots & \vdots & \ddots & \vdots \\
0 & 0 & \cdots & 1 & 0 & 0 & \cdots & 0
\end{array}\right]_{N \times 2 N}
\end{aligned}
$$

Setting the sampling interval to $\Delta T$ and the discrete state-space and observation equations of the system yield

$$
\begin{gathered}
\boldsymbol{X}(k+1)=\boldsymbol{\Phi} \boldsymbol{X}(k)+\boldsymbol{\Gamma}[\boldsymbol{F}(k)+\boldsymbol{w}(k)], \\
\boldsymbol{Z}(k)=\boldsymbol{H} \boldsymbol{X}(k)+\boldsymbol{v}(k),
\end{gathered}
$$

where $\quad \boldsymbol{\Gamma}=\int_{k \Delta T}^{(k+1) \Delta T} \exp \{\boldsymbol{A}[(k+1) \Delta T-\tau]\} \boldsymbol{B} d \tau \quad$, $\boldsymbol{\Phi}=\exp (\boldsymbol{A \Delta T})$. These two Gaussian white noise sequences, $\boldsymbol{w}(k)$ and $\boldsymbol{v}(k)$, are irrelevant to each other. The characteristics of noise are $E[\boldsymbol{w}(k)]=0$, $E\left[\boldsymbol{w}(k) \boldsymbol{w}^{\mathrm{T}}(j)\right]=\boldsymbol{Q}_{v} \delta_{k, j} \quad, \quad \boldsymbol{Q}_{v}=Q \boldsymbol{I}_{N \times N} \quad, \quad E[\boldsymbol{v}(k)]=0$, $E\left[\boldsymbol{v}(k) \boldsymbol{v}^{\mathrm{T}}(j)\right]=\boldsymbol{R}_{v} \delta_{k, j}, \boldsymbol{R}_{v}=R \boldsymbol{I}_{N \times N}, R=\sigma^{2} . \quad Q$ and $R$ are covariance matrix. $\boldsymbol{I}_{N \times N}$ is the identity matrix. $\delta_{k, j}$ the kronecker delta function, $\delta_{k, j}=1$ when $k=j, \delta_{k, j}=0$ when $k \neq j$. In the description of noise characteristics in the following sections, it is expressed by different $Q$ and $\sigma$.

\section{Excitation force identification of active de- vice with Kalman filter}

In the previous section, the modal coordinates of the car body were used as observation objects, and the discrete-time state-space equation and observation equation of the flexible car body were established based on the modal superposition method. In this section, the modal force of the flexible car body is first identified based on the state equation and Kalman filter, and then the active device excitation force is determined.

The basic equation of Kalman filter is in a recursive form in the time domain. Its computation is a continuous "prediction-correction" process, where substantial data storage is not required during solving. Therefore, the method is very suitable for real-time processing and computer implementation. The fundamental equations of Kalman filter are shown in Eq. (12)-(18).

State prediction

$$
\overline{\boldsymbol{X}}(k / k-1)=\boldsymbol{\Phi} \overline{\boldsymbol{X}}(k-1 / k-1),
$$

Error covariance of state prediction

$$
\boldsymbol{P}(k / k-1)=\boldsymbol{\Phi} \boldsymbol{P}(k-1 / k-1) \boldsymbol{\Phi}^{\mathrm{T}}+\boldsymbol{\Gamma} \boldsymbol{Q} \boldsymbol{\Gamma}^{\mathrm{T}},
$$

Innovation

$$
\overline{\boldsymbol{Z}}(k)=\boldsymbol{Z}(k)-\boldsymbol{H} \overline{\boldsymbol{X}}(k / k-1),
$$

Innovation covariance

$$
\boldsymbol{S}(k)=\boldsymbol{H P}(k / k-1) \boldsymbol{H}^{\boldsymbol{T}}+\boldsymbol{R},
$$

Kalman gain

$$
\boldsymbol{K}_{\mathrm{a}}(k)=\boldsymbol{P}(k / k-1) \boldsymbol{H}^{T} \boldsymbol{S}^{-1}(k),
$$

State vector update

$$
\overline{\boldsymbol{X}}(k / k)=\overline{\boldsymbol{X}}(k / k-1)+\boldsymbol{K}_{\mathrm{a}}(k) \overline{\boldsymbol{Z}}(k),
$$

Covariance matrix update 


$$
\boldsymbol{P}(k / k)=\left[\boldsymbol{I}-\boldsymbol{K}_{\mathrm{a}}(k) \boldsymbol{H}\right] \boldsymbol{P}(k / k-1),
$$

where $I$ is the identity matrix.

The identification algorithm uses the Kalman gain, innovation, and covariance generated by Kalman filter to estimate the excitation force. The fundamental equations are shown in Eq. (19)-(25).

Sensitivity matrix

$$
\begin{gathered}
\boldsymbol{B}_{\mathrm{s}}(k)=\boldsymbol{H}\left[\boldsymbol{\Phi} \boldsymbol{M}_{\mathrm{s}}(k-1)+\boldsymbol{I}\right] \boldsymbol{\Gamma}, \\
\boldsymbol{M}_{\mathrm{s}}(k)=\left[\boldsymbol{I}-\boldsymbol{K}_{\mathrm{a}}(k) \boldsymbol{H}\right]\left[\boldsymbol{\Phi} \boldsymbol{M}_{\mathrm{s}}(k-1)+\boldsymbol{I}\right],
\end{gathered}
$$

Gain matrix

$$
\begin{aligned}
\boldsymbol{K}_{\mathrm{b}}(k)= & \gamma^{-1} \boldsymbol{P}_{\mathrm{b}}(k-1) \boldsymbol{B}_{\mathrm{s}}^{\mathrm{T}}(k) \times \\
& {\left[\boldsymbol{B}_{\mathrm{s}}(k) \gamma^{-1} \boldsymbol{P}_{\mathrm{b}}(k-1) \boldsymbol{B}_{\mathrm{s}}^{\mathrm{T}}(k)+\boldsymbol{S}(k)\right]^{-1}, }
\end{aligned}
$$

Excitation force identification value

$$
\hat{\boldsymbol{F}}(k)=\hat{\boldsymbol{F}}(k-1)+\boldsymbol{K}_{\mathrm{b}}(k)\left[\overline{\boldsymbol{Z}}(k)-\boldsymbol{B}_{\mathrm{s}}(k) \hat{\boldsymbol{F}}(k-1)\right],
$$

Error covariance

$$
\boldsymbol{P}_{\mathrm{b}}(k)=\left[\boldsymbol{I}-\boldsymbol{K}_{\mathrm{b}}(k) \boldsymbol{B}_{\mathrm{s}}(k)\right] \gamma^{-1} \boldsymbol{P}_{\mathrm{b}}(k-1),
$$

where, $\gamma$ is an attenuation factor, and the value of $\gamma$ will affect the speed of adaptive tracking time-varying parameters.

The excitation force identified by Eq. (19)-(23) is the modal force of car body, that is,

$$
\left[\begin{array}{c}
F_{Y_{1}} \\
F_{Y_{2}} \\
\vdots \\
F_{Y_{N}}
\end{array}\right]=\left[\begin{array}{c}
F_{\mathrm{s} 1}\left(x_{\mathrm{s} 1}, t\right) Y_{1}\left(x_{\mathrm{s} 1}\right)+F_{\mathrm{s} 2}\left(x_{\mathrm{s} 2}, t\right) Y_{1}\left(x_{\mathrm{s} 2}\right)+\sum_{i=1}^{n} F_{i}\left(x_{i}, t\right) Y_{1}\left(x_{i}\right) \\
F_{\mathrm{s} 1}\left(x_{\mathrm{s} 1}, t\right) Y_{2}\left(x_{\mathrm{s} 1}\right)+F_{\mathrm{s} 2}\left(x_{\mathrm{s} 2}, t\right) Y_{2}\left(x_{\mathrm{s} 2}\right)+\sum_{i=1}^{n} F_{i}\left(x_{i}, t\right) Y_{2}\left(x_{i}\right) \\
\vdots \\
F_{\mathrm{s} 1}\left(x_{\mathrm{s} 1}, t\right) Y_{N}\left(x_{\mathrm{s} 1}\right)+F_{\mathrm{s} 2}\left(x_{\mathrm{s} 2}, t\right) Y_{N}\left(x_{\mathrm{s} 2}\right)+\sum_{i=1}^{n} F_{i}\left(x_{i}, t\right) Y_{N}\left(x_{i}\right)
\end{array}\right]
$$

Since the secondary suspension of car body is subjected only to the static load, the following holds when the devices on the car body are arranged symmetrically with respect to the center of car body

$$
F_{s 1}=F_{s 2}=\frac{1}{2} m_{\mathrm{b}} g+\frac{1}{2} \sum_{i}^{n} m_{\mathrm{e} i} g
$$

when $N \geq n$, that is, when the number of modes involved in the computation is not less than the number of excitation forces, we can derive the excitation forces of active devices by substituting Eq. (25) into Eq. (24).

\section{Modal order selection method based on tolerance index}

The identification error that may be caused by the improper modal order selection in this section is studied to improve the recognition accuracy. Although the structure has infinite-order modes in theory, the ones actually excited are finite-order modes, which are low-order modes in general. During solution of the modal coordinate response of car body by the modal superposition method, as shown in Eq. (4), if the selected modal order is greater than or equal to the actually excited modes of structure, the modal order selection will have little impact on the computation result of modal coordinate response. Contrastively, if the selected modal order is less than the actually excited modes of structure, it will inevitably produce a marked impact on the response computation result, thereby affecting the result of excitation force identification.

Suppose there is an active device installed under the chassis of car body, and its position coordinate is $x_{\mathrm{e}}=L / 2$. The excitation force of active device is $F=2000 \sin (40 \pi t)$. Seventeen measuring points are arranged at the car body, which are numbered $1,2 \ldots 17$, respectively. Their coordinate positions are $4.5,5.5,6.5,7.5,8.5,9.5,10.5,11.5,12.5,13.5$, $14.5,15.5,16.5,17.5,18.5,19.5$ and 20.5 , respectively. In Table 1, the parameters of car body and device are listed.

Table 1 Parameters of car body and device

\begin{tabular}{llll}
\hline \multicolumn{1}{c}{ Physical quantity } & Symbol & Unit & Value \\
\hline $\begin{array}{l}\text { Equivalent bending } \\
\text { stiffness of car body }\end{array}$ & $E I$ & $\mathrm{~N} \cdot \mathrm{m}^{2}$ & $5.0 \times 10^{9}$ \\
$\begin{array}{l}\text { section } \\
\text { Mass per unit length of } \\
\text { car body }\end{array}$ & $\rho$ & $\mathrm{kg} / \mathrm{m}$ & 1040 \\
$\begin{array}{l}\text { Car body mass } \\
\text { Car body length }\end{array}$ & $m_{\mathrm{b}}$ & $\mathrm{kg}$ & $26.0 \times 10^{3}$ \\
$\begin{array}{l}\text { Position of secondary } \\
\text { suspension on the left } \\
\text { side }\end{array}$ & $x_{\mathrm{s} 1}$ & $\mathrm{~m}$ & 25 \\
$\begin{array}{l}\text { Position of secondary } \\
\text { suspension on the right }\end{array}$ & $x_{\mathrm{s} 2}$ & $\mathrm{~m}$ & 3.5 \\
$\begin{array}{l}\text { side } \\
\begin{array}{l}\text { Device mass } \\
\text { Hyesterical damping of } \\
\text { car body }\end{array}\end{array}$ & $m_{\mathrm{e}}$ & $\mathrm{kg}$ & 21.5 \\
\hline
\end{tabular}

Initial parameters are set for the excitation force 
identification method proposed in Section 3. The initial state value is $\overline{\boldsymbol{X}}(0)=$ zeros $(n, 1)$, the initial excitation force is $\hat{\boldsymbol{F}}(k)=\operatorname{zeros}(n, 1) \quad$, the initial sensitivity matrix is $\boldsymbol{M}_{\mathrm{s}}=100 \times \operatorname{eye}(n)$, the characteristics of noise are $Q=10^{-2}$ and $\sigma=10^{-12}$, and the attenuation factor is $\gamma=0.1$. Other parameters are $\boldsymbol{P}(0)=10^{10} \times$ eye $(n), \boldsymbol{P}_{\mathrm{b}}(0)=8^{10} \times$ eye $(n)$. In the present computation, the sampling interval of response data is $\Delta T=0.001 \mathrm{~s}$. The response of some measurement points of the car body is shown in Figure 2. The measurement points of different positions have different response levels. They all first undergo an initial shock process and then enter a steady-state vibration process.

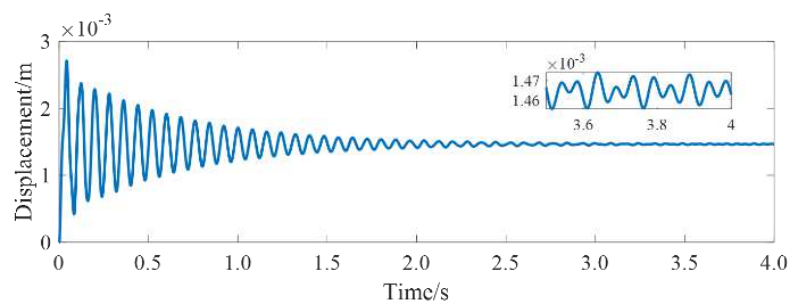

(a) measurement point 1

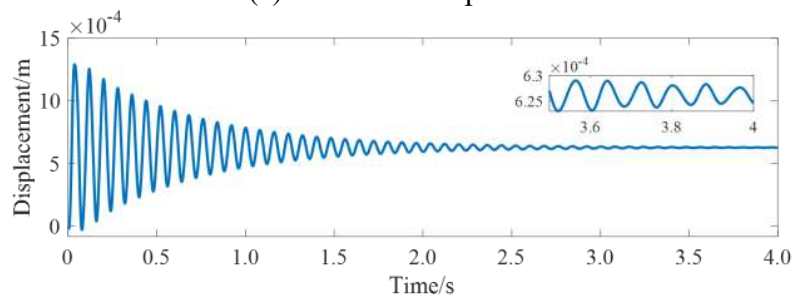

(b) measurement point 5

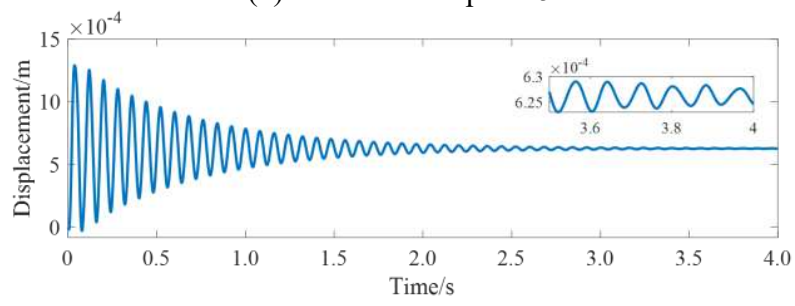

(c) measurement point 9

Figure 2 The response of some measurement points of car body

Next, the excitation force of the device is identified with the measurement point response data. Assuming that the excitation force of active device elicits the prior 4-order flexible modes of car body. Let the selected modal order be $N$. When $N=2, N=3, N=4, N=5$, the identification results of the excitation force are shown in Figure 3. As is clear, poor identification results are yielded when the prior 2 and 3 -order modes are selected, while rather accurate identification results are attained when the prior 4 and 5order modes are selected. It shows that the modal order selection has a significant impact on the accuracy of identification results.

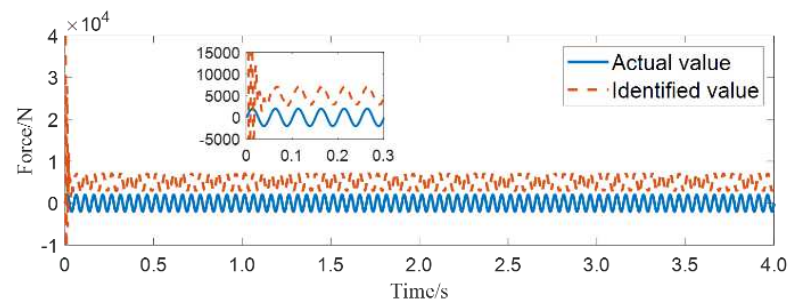

(a) $N=2$

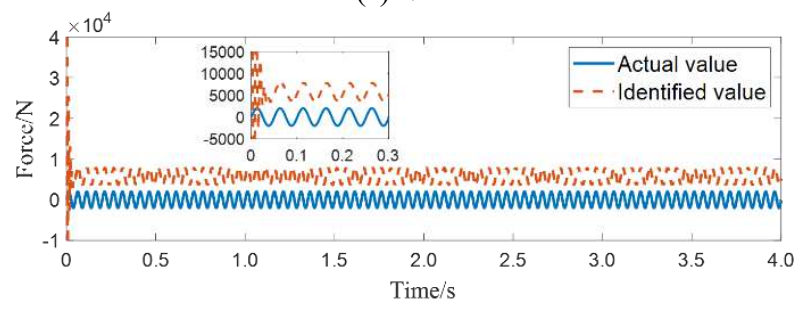

(b) $N=3$

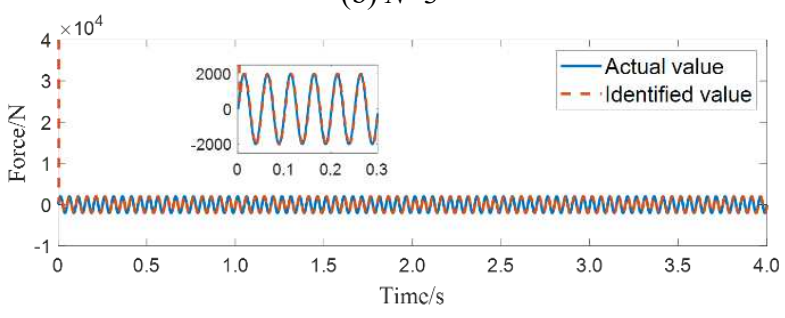

(c) $N=4$

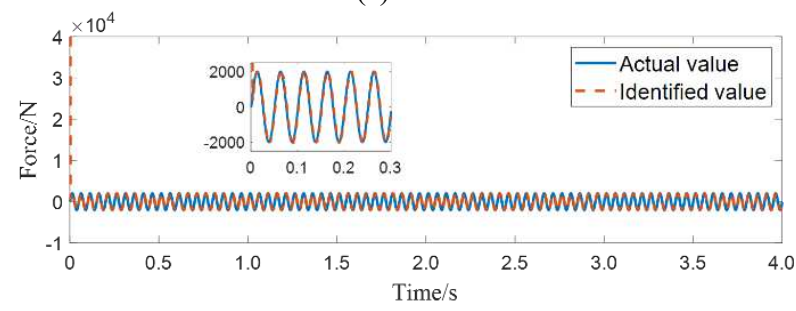

(d) $N=5$

Figure 3 Identification results of the excitation force

Thus, a practical method of selecting modal order is put forward, as shown in Figure 4. First of all, for the actual car body physical coordinate response $Z$ caused by the excitation force of actual active device, the prior $\mathrm{N}$-order modes are selected, and the Eq. (4) is used to calculate the car body modal coordinate response. The excitation force is identified using the excitation force identification algorithms, Eq. (12)-(25). Then the prior $N+1$-order modes are selected to calculate the corresponding car body mode coordinate response based on the excitation force obtained at this time by Eq. (5)-(9). And the corresponding physical coordinate response $z$ is obtained via Eq. (3). The relative error is calculated between the actual car body physical coordinate response $Z$ and the physical coordinate response $z$ obtained. If it is less than the tolerance $\mathrm{Tol}$, the modal order is selected to be $N$, otherwise $N=N+1$ is used to perform 
the cyclic calculation again.

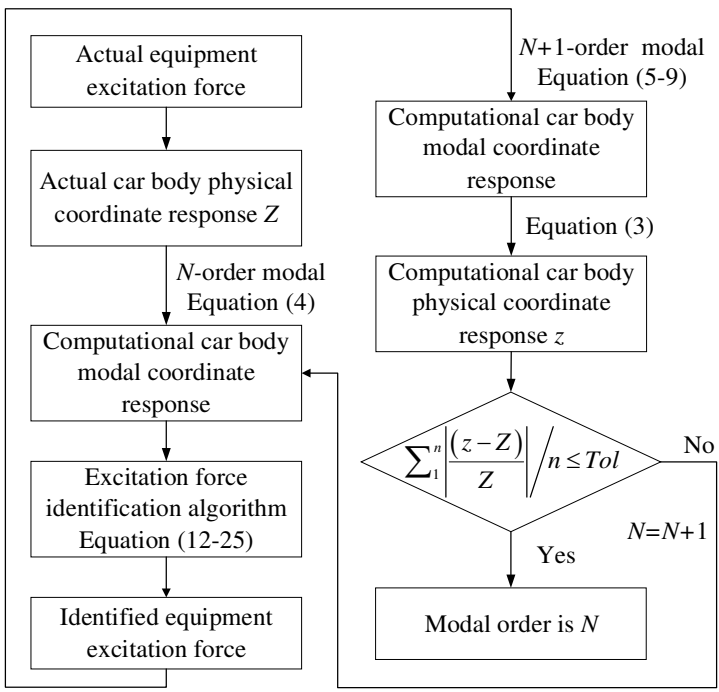

Figure 4 Modal order selection method

The modal order selection experiment is carried out using the above method. In a similarly way, tolerance computation is performed by selecting the prior 2, 3, 4 and 5-order modes, respectively, after assuming that the device excitation force elicits the prior 4-order modes of car body. Table 2 lists the selected modal order and the corresponding tolerance. The tolerance is relatively large when the prior 2 and 3 -order modes are selected for computation, while is relatively small when the prior 4 and 5-order modes are selected for computation. The tolerances are well consistent with the excitation force identification results in Fig. 3. That is, the larger the tolerance, the lower the identification accuracy, and vice versa. Additionally, the tolerance stabilizes at a small value when the selected modal order is 4 and 5 . Therefore, the modal order can be determined just through iterative computations by the modal order selection method shown in Figure 4 without needing to pre-define the magnitude of tolerance Tol. A modal order of 4 is appropriate according to the results shown in Table 2.

Table 2 Selected modal order and corresponding tolerance

\begin{tabular}{lll}
\hline & Modal order & Tolerance \\
\hline 2 & & 0.0229 \\
3 & 0.0373 & \\
4 & 0.0047 & \\
5 & 0.0046 & \\
\hline
\end{tabular}

\section{Active excitation force identification}

In order to verify the effectiveness of the above excitation force identification method, for single and multiple active devices installed under the chassis, single-frequency steadystate, multi-frequency steady-state, impact, sawtooth wave and square wave excitation forces are applied respectively. And the measurement point response is sequentially added with different levels of Gaussian white noise. The vehicle body and device parameters used in simulation test of active excitation force identification are shown in Table 1. The initial parameter settings are consistent with Section 4. In order to analyze the accuracy of identification, the allowable error range is defined as $5 \%$, that is, the error of $+5 \%$ relative to the actual value of the excitation force is the upper limit, and the error of $-5 \%$ relative to the actual value of the excitation force is the lower limit.

\subsection{Excitation force identification for single active device}

The scenario in which a single active device is mounted under the chassis of car body is studied first. Setting the position coordinates as $x=L / 2$. The noise characteristics are $\sigma=10^{-9}, \sigma=10^{-10}, \sigma=10^{-11}, \sigma=10^{-12}$. Figure 5-9 below illustrate the excitation force identification results for the device, which includes the upper error limit curve and the lower error limit curve relative to the actual value. As is clear, noise characteristics have a significant impact on identification results. The identification results of excitation forces improve gradually with the decreasing standard deviation of measurement noise. When $\sigma=10^{-9}$, both the amplitude and phase identification results of excitation force are poor, which obviously deviates from the error limit. When $\sigma=10^{-12}$, ideal excitation force identification result is achieved, and the identification value is kept within error limits. So, when the noise characteristic $\sigma$ is small, this method is suitable for the identification of various steadystate and transient-state excitation forces.

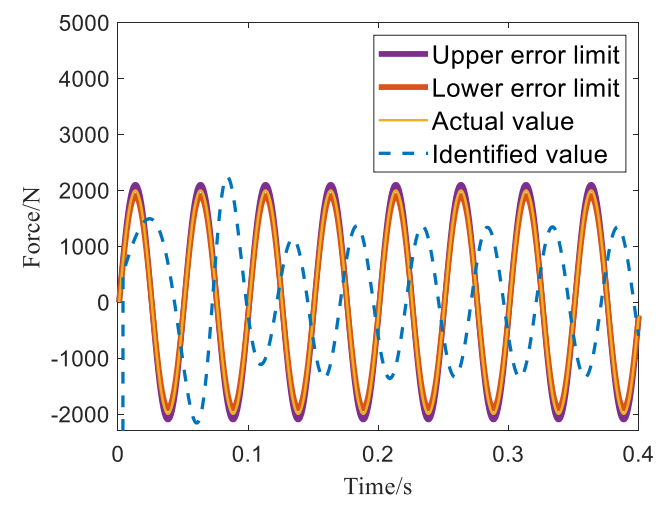

(a) $\sigma=10^{-9}$ 


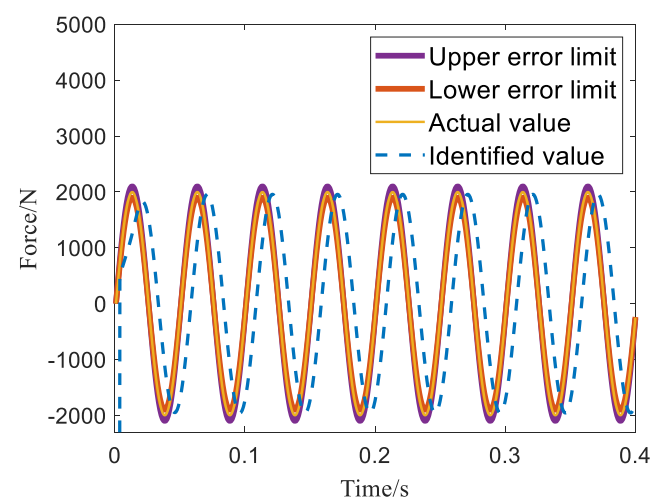

(b) $\sigma=10^{-10}$

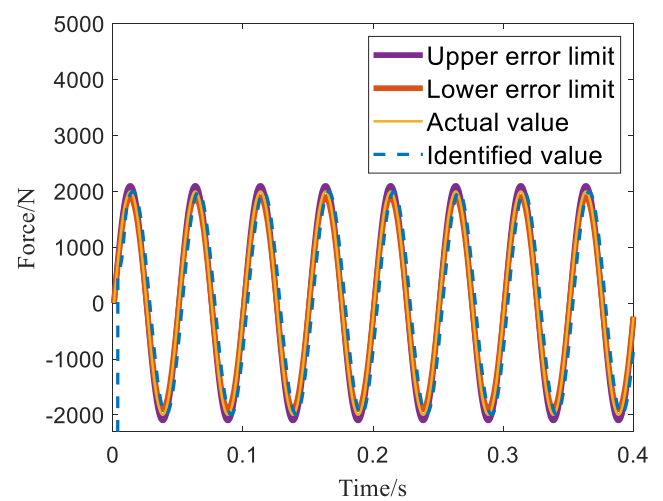

(c) $\sigma=10^{-11}$

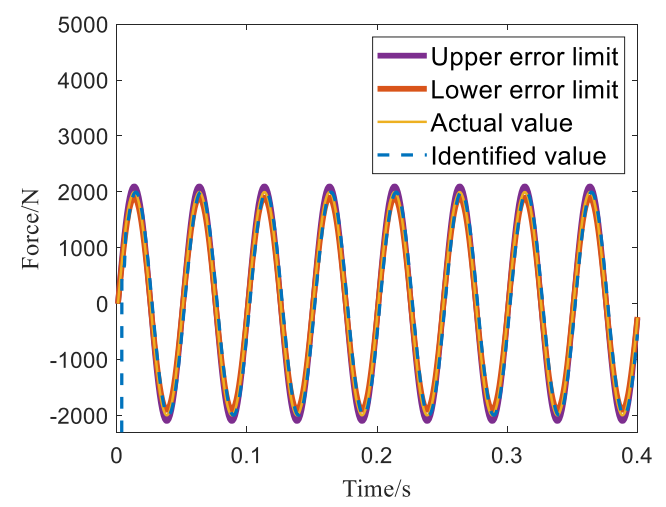

(d) $\sigma=10^{-12}$

Figure 5 Identification results of excitation force, singlefrequency steady-state excitation force, $F=2000 \sin (40 \pi t)$

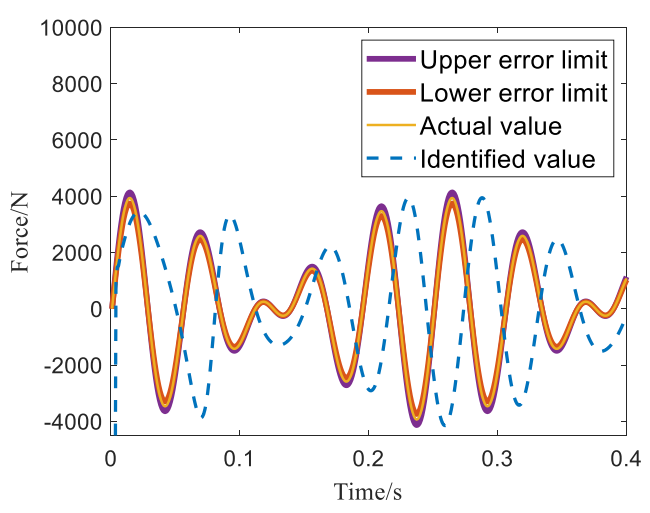

(a) $\sigma=10^{-9}$

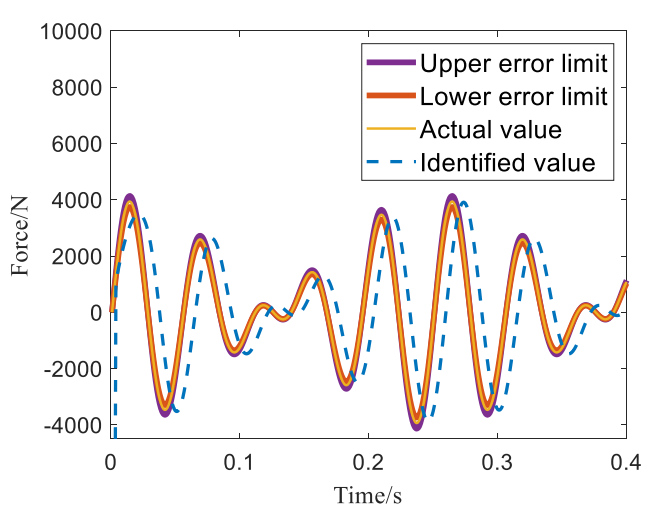

(b) $\sigma=10^{-10}$

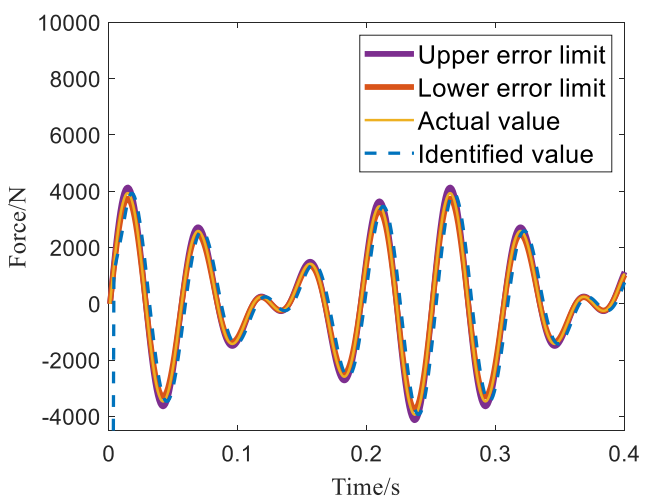

(c) $\sigma=10^{-11}$

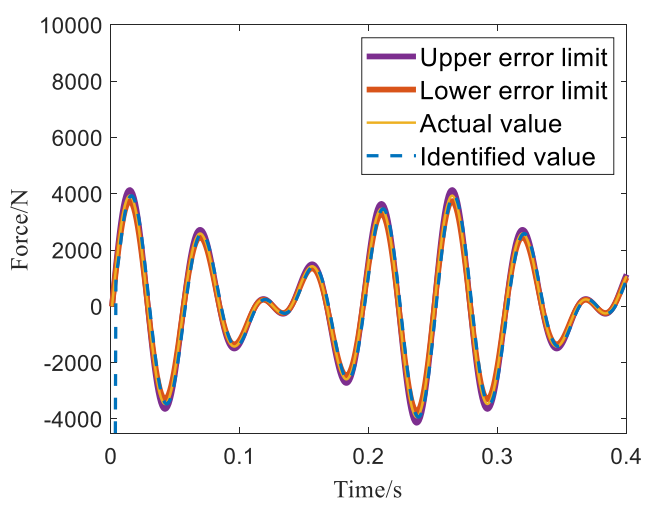

(d) $\sigma=10^{-12}$ 
Figure 6 Identification results of excitation force, multifrequency steady-state excitation force,

$$
F=2000 \times(\sin (32 \pi t)+\sin (40 \pi t))
$$

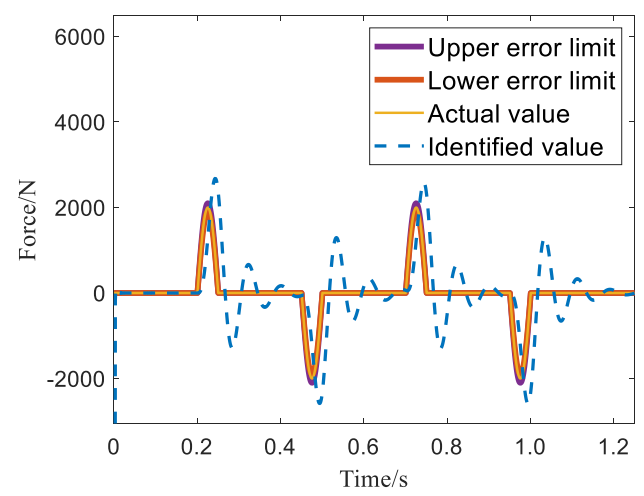

(a) $\sigma=10^{-9}$

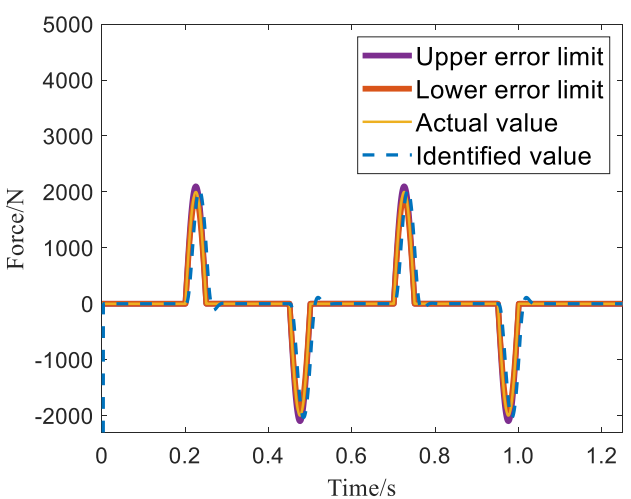

(b) $\sigma=10^{-10}$

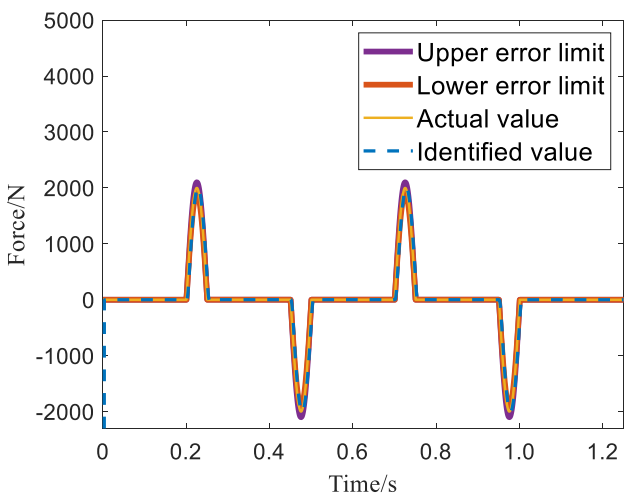

(c) $\sigma=10^{-11}$

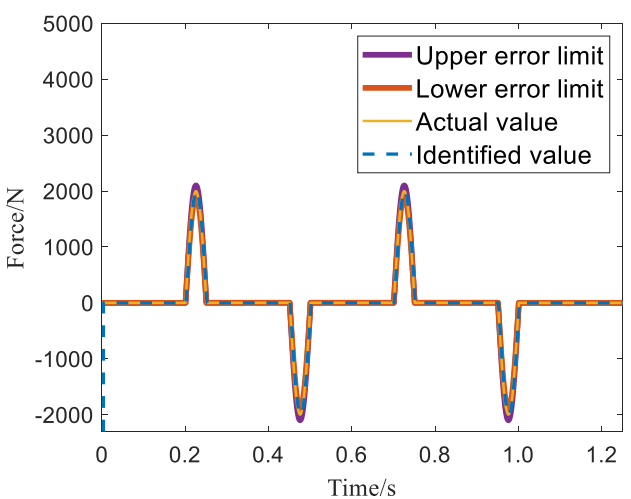

(d) $\sigma=10^{-12}$

Figure 7 Identification results of excitation force, impact excitation force

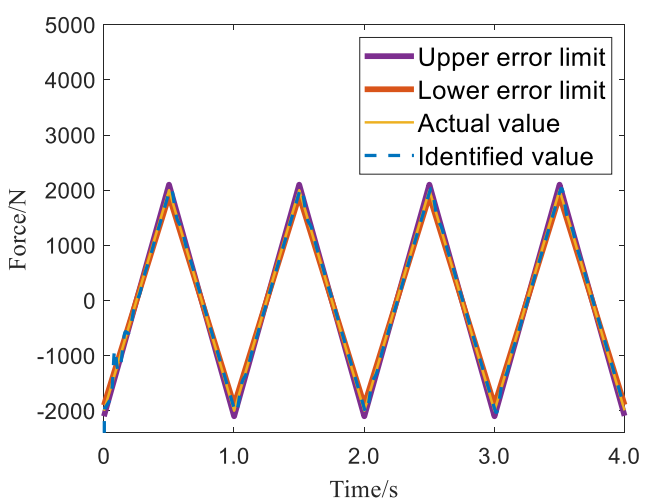

(a) $\sigma=10^{-9}$

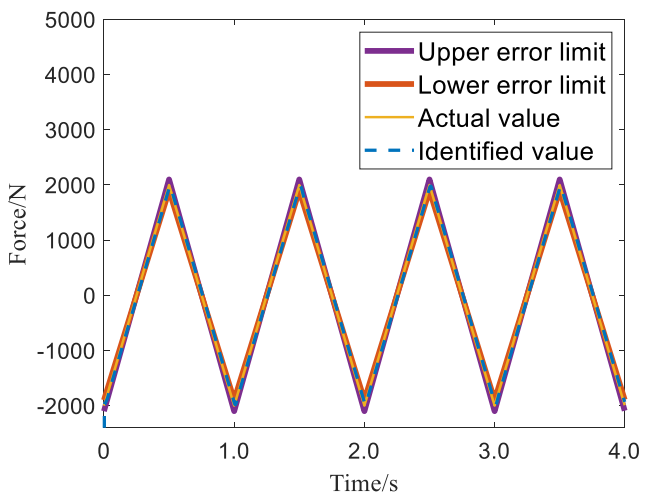

(b) $\sigma=10^{-10}$ 


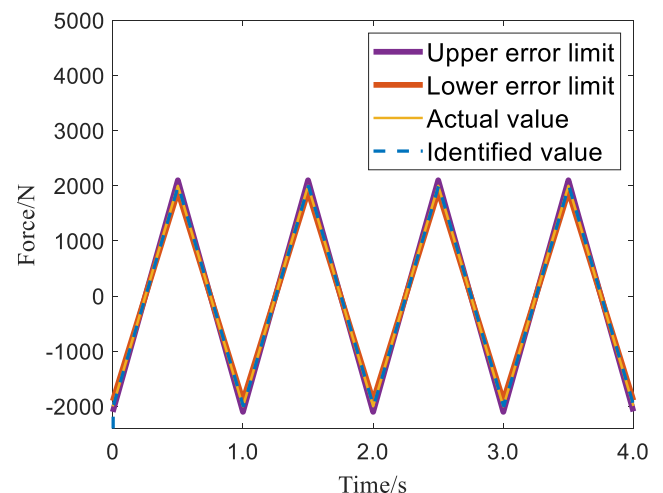

(c) $\sigma=10^{-11}$

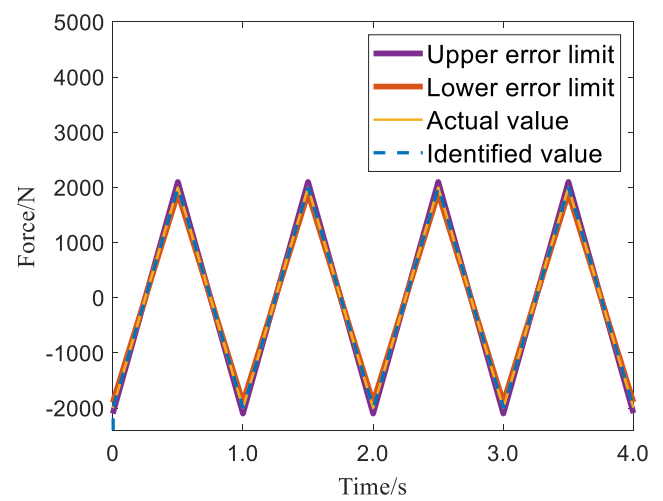

(d) $\sigma=10^{-12}$

Figure 8 Identification results of excitation force, sawtooth wave excitation force

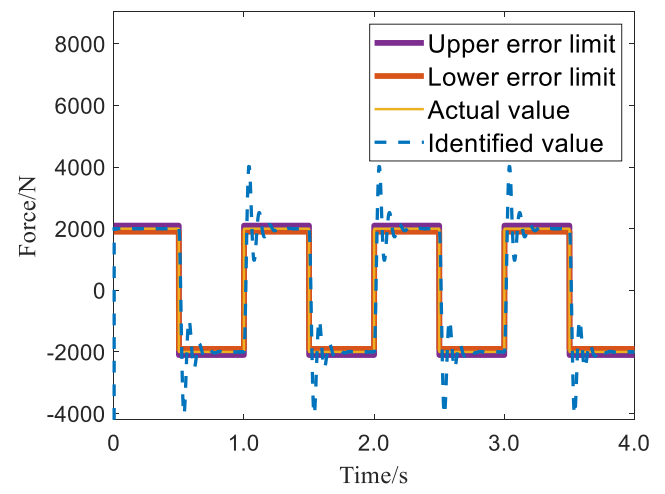

(a) $\sigma=10^{-9}$

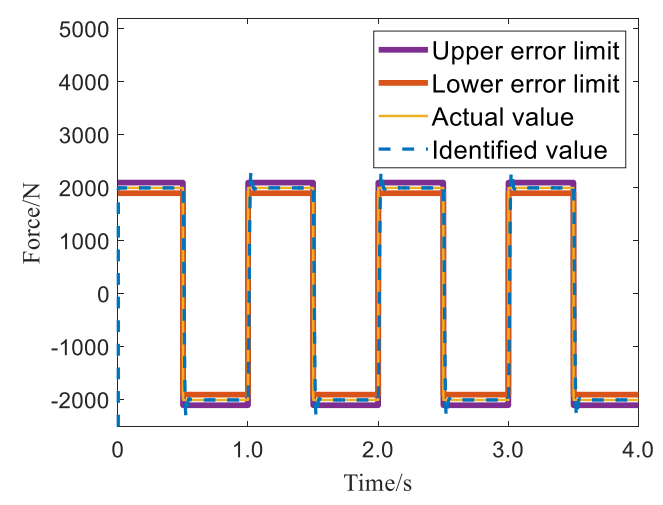

(b) $\sigma=10^{-10}$

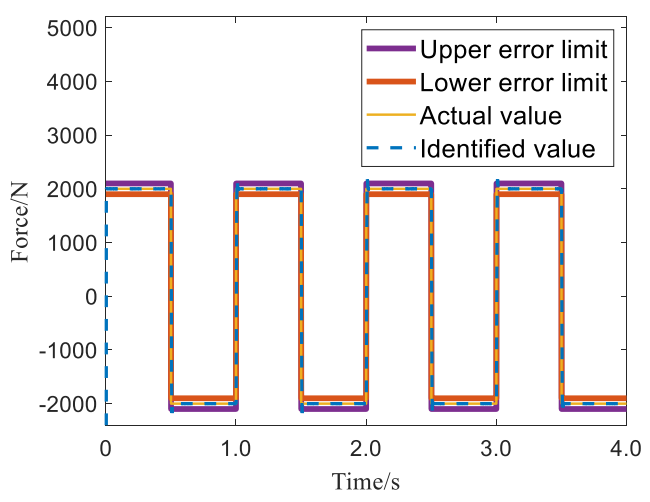

(c) $\sigma=10^{-11}$

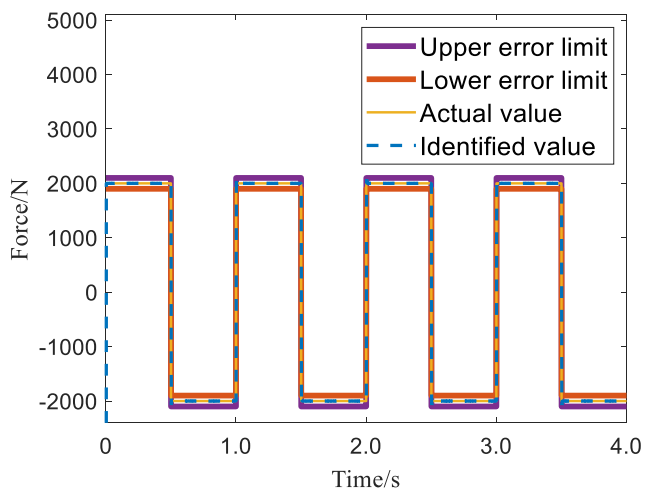

(d) $\sigma=10^{-12}$

Figure 9 Identification results of excitation force, square wave excitation force

\subsection{Excitation force identification for multiple active devices}

The scenario in which multiple active devices are mounted under the chassis of car body is considered then. Assuming that there are two devices in total, whose position coordinates are $x_{1}=L / 3$ and $x_{2}=2 L / 3$, respectively. The noise characteristic is $\sigma=10^{-12}$. Figure 10-14 below illustrate the excitation force identification results. It can be seen that 
under certain noise condition, the excitation force identification algorithm still has a good effect for the case where multiple active devices are installed under the chassis of car body. The identified values of the excitation forces, $F_{1}$ and $F_{2}$, are within the allowable error limit.

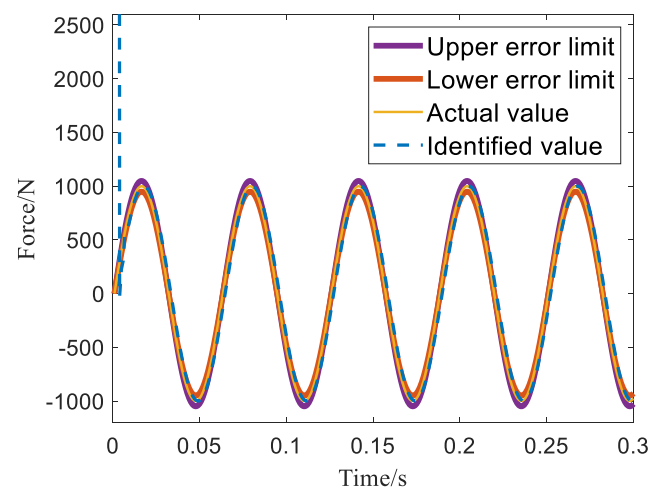

(a) $F_{1}=1000 \times \sin (32 \pi t)$

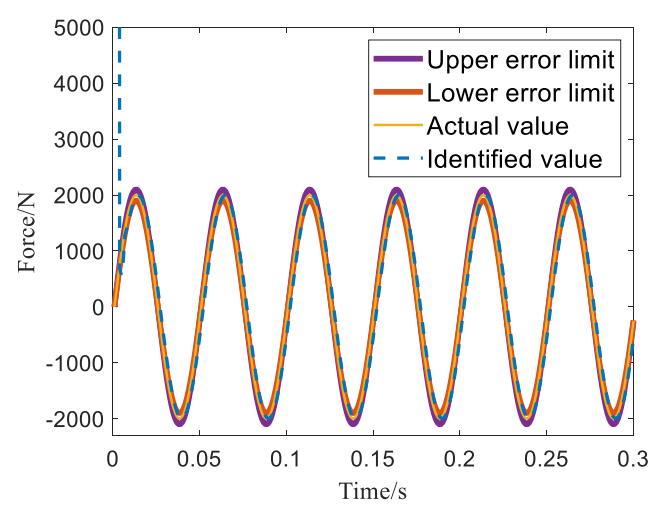

(b) $F_{2}=2000 \times \sin (40 \pi t)$

Figure 10 Identification results of excitation force, singlefrequency steady-state excitation force

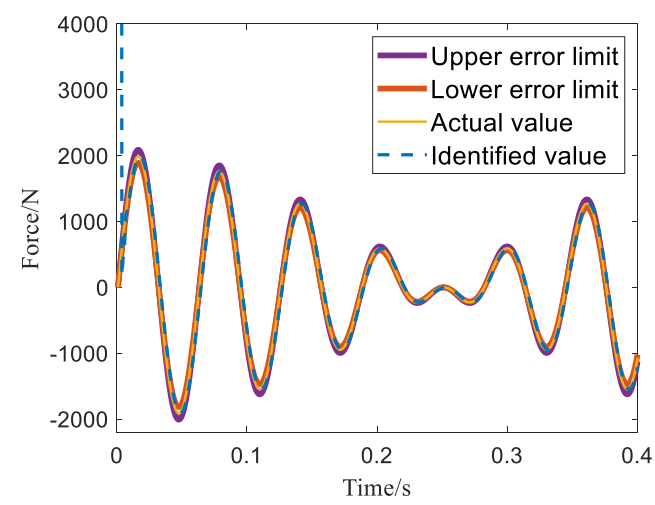

(a) $F_{1}=1000 \times(\sin (30 \pi t)+\sin (34 \pi t))$

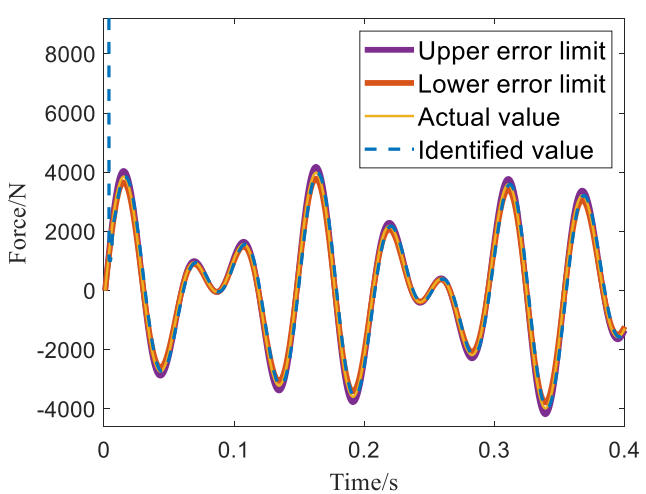

(b) $F_{2}=2000 \times(\sin (28 \pi t)+\sin (40 \pi t))$

Figure 11 Identification results of excitation force, multifrequency steady-state excitation force

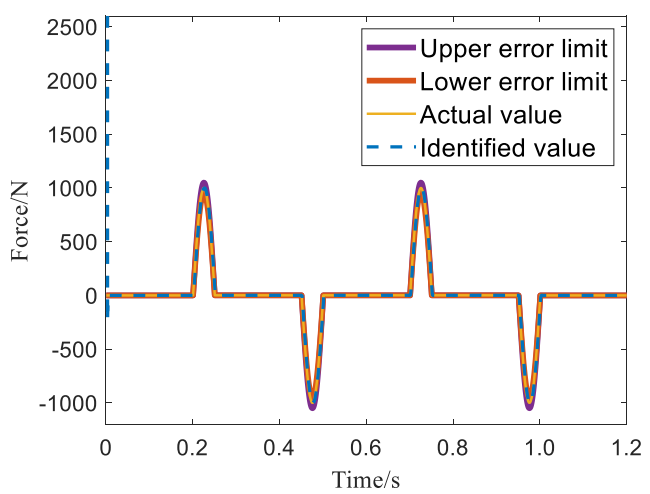

(a) $F_{1}$

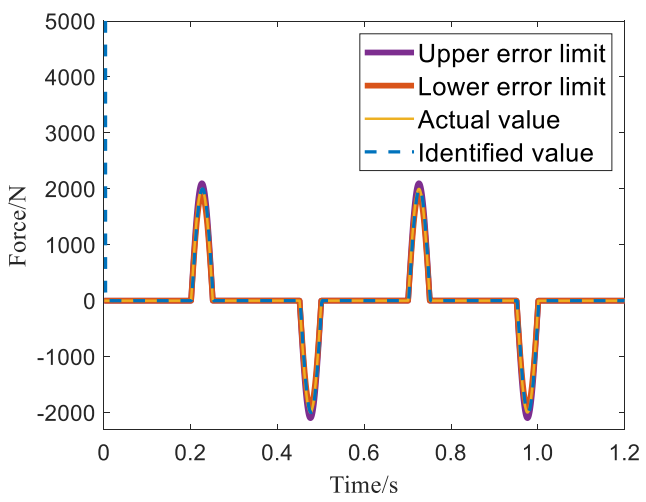

(b) $F_{2}$

Figure 12 Identification results of excitation force, impact excitation force 


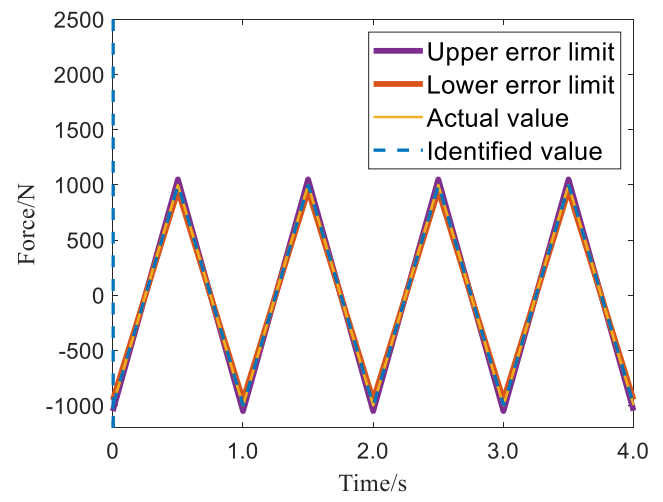

(a) $F_{1}$

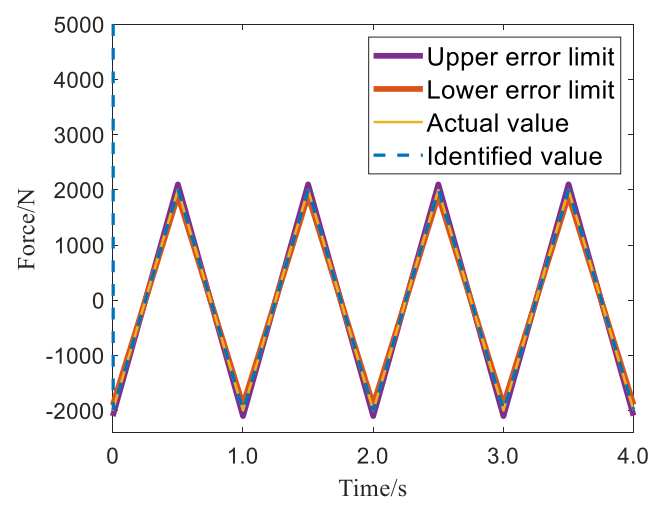

(b) $F_{2}$

Figure 13 Identification results of excitation force, sawtooth wave excitation force

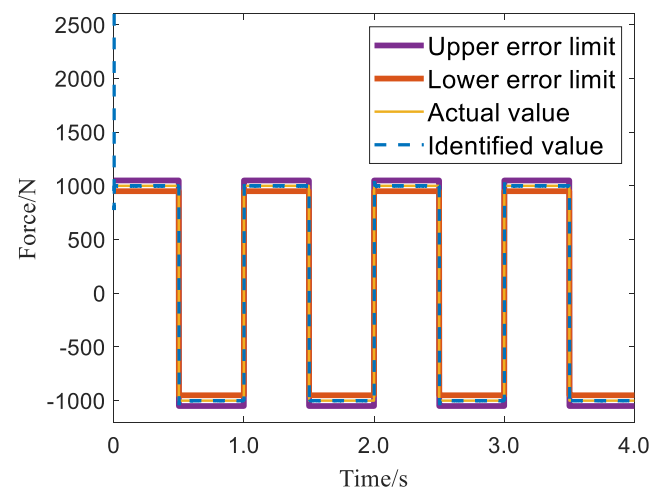

(a) $F_{1}$

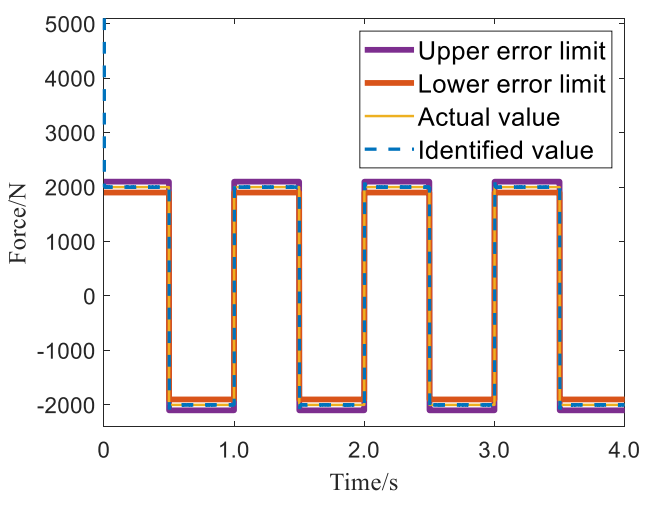

(b) $F_{2}$

Figure 14 Identification results of excitation force, square wave excitation force

\section{Conclusions}

The vertical dynamic coupling model of car body and underchassis device is built and the excitation force of active device of railway vehicle is identified by combining the modal superposition method and Kalman filter in this paper. Furthermore, a modal order selection method is developed for improving the identification accuracy based on tolerance index. The simulation results show that the method is suitable for the identification of various steady-state and transient-state excitation forces, and the recognition results of single and multiple active devices excitation forces have good accuracy. The identified values are within the allowable error limit. Excitation force identification is crucial to the precise design of vibration reduction for active device under car body of high-speed train. In the future work, the field test of a high-speed train will be carried out with this identification method.

\section{Declaration}

\section{Acknowledgements}

Not applicable

\section{Funding}

Supported by National Natural Science Foundation of China (Grant No. 51805373)

\section{Availability of data and materials}

The datasets supporting the conclusions of this article are included within the article.

\section{Authors' contributions}

The author' contributions are as follows: Jiang-Xue Chen 
was in charge of the whole trial; Dao Gong wrote the manuscript; Jin-Song Zhou assisted with sampling and laboratory analyses.

\section{Competing interests}

The authors declare no competing financial interests.

\section{Consent for publication}

Not applicable

\section{Ethics approval and consent to participate}

Not applicable

\section{References}

[1] Foo E, Goodall R M. Active suspension control of flexible-bodied railway vehicles using electro-hydraulic and electro-magnetic actuators. Control Engineering Practice, 2000, 8(5):507-518.

[2] Gong D, Zhou J and Sun W. On the resonant vibration of a flexible railway car body and its suppression with a dynamic vibration absorber. Journal of Vibration and Control, 2013, 19(5):649 -657.

[3] Uhl T. The inverse identification problem and its technical application. Archive of Applied Mechanics, 2007, 77(5):325-337.

[4] Inoue H, Harrigall J J and Reid S R. Review of inverse analysis for indirect measurement of impact force. Applied Mechanics Reviews, 2001, 54(6):503-524.

[5] Yan G, Zhou L. Impact load identification of composite structure using genetic algorithms. Journal of Sound and Vibration, 2009, 319(3-5):869-884.

[6] Zhang E, Antoni J, Feissel P. Bayesian force reconstruction with an uncertain model. Journal of Sound and Vibration, 2012, 331(4):798814.

[7] Qiao B, Zhang X, Luo X, et al. A force identification method using cubic B-spline scaling functions. Journal of Sound and Vibration, 2015, 337:28-44

[8] Lai $\mathrm{T}$, Yi $\mathrm{T} \mathrm{H}$ and $\mathrm{Li} \mathrm{H} \mathrm{N}$. Parametric study on sequential deconvolution for force identification. Journal of Sound and Vibration, 2016, 377:76-89.

[9] Chen J X, Gong D, Zhou J S, et al. Identification of physical and excitation parameters of under-chassis equipment for railway vehicles. Journal of Vibration and Acoustics, 2020, 142(3):1-9.

[10] F D Barlett Jr, W G Flannelly. Model verification of force determination for measuring vibration loads. Journal of the American Helicopter Society, 1979, 19(4):10-18.

[11] Gunawan F E, Homma H and Morisawa Y. Impact force estimation by quadratic spline approximation. Journal of Solid Mechanics and Materials Engineering, 2008, 2(8):1092-1103.

[12] Liu J, Sun X, Han X, et al. Dynamic load identification for stochastic structures based on Gegenbauer polynomial approximation and regularization method. Mechanical Systems and Signal Processing, 2015. 56-57:35-54.

[13] Samagassi S, Khamlichi A, Driouach A, et al. Reconstruction of multiple impact forces by wavelet relevance vector machine approach Journal of Sound and Vibration, 2015(359):56-67.

[14] Kazemi M, Hematiyan M R, Ghavami K. An efficient method for dynamic load identification based on structural response. International Conference on Engineering Optimization, Rio de Janeiro, Brazil, 1-5 June 2008, 1-6.

[15] Aucejo M. Structural source identification using a generalized Tikhonov regularization. Journal of Sound and Vibration, 2014, 333(22):5693-5707.

[16] Yu L, Chan T H T. Moving force identification based on the frequency-time domain method. Journal of Sound and Vibration, 2003, 261(2):329-349.

[17] Thite A N, Thompson D J. The quantification of structure-borne transmission paths by inverse methods. Part 1: Improved singular value rejection methods. Journal of Sound and Vibration, 2003, 264(2):411-431.

[18] Hansen P C. Analysis of Discrete Ill-Posed Problems by Means of the L-Curve. Siam Review, 1992, 34(4):561-580.

[19] Jacquelin E, Bennani A, Hamelin P. Force reconstruction: analysis and regularization of a deconvolution problem. Journal of Sound and Vibration, 2003, 265(1):81-107.

[20] Liu Y, Jr W S S. Reducing the impact of measurement errors when reconstructing dynamic forces. Journal of Vibration and Acoustics, 2006, 128(5):586-593.

[21] Choi H G, Thite A N, Thompson D J. Comparison of methods for parameter selection in Tikhonov regularization with application to inverse force determination. Journal of Sound and Vibration, 2007, 304(3-5):894-917.

[22] Qiao B, Liu J, Liu J, et al. An enhanced sparse regularization method for impact force identification. Mechanical Systems and Signal Processing, 2019, 126:341-367.

[23] Ma C, Tuan P, Lin D, Liu C. A study of an inverse method for the estimation of impulsive loads. International Journal of Systems Science. 1998, 29(6): 663-672.

[24] Ma C K, Lin D C. Input forces estimation of a cantilever beam. Inverse Problems in Science and Engineering, 2000, 8(6):511-528.

[25] Kalman R E. A New Approach to Linear Filtering and Prediction Problems. Journal of Basic Engineering. 1960, 82(1): 35-45.

[26] Ma C K, Ho C C. An inverse method for the estimation of input forces acting on non-linear structural systems. Journal of Sound and Vibration, 2004, 275: 953-971.

[27] Lin D C. Input estimation for nonlinear systems. Inverse Problems in Science and Engineering, 2010, 18(5): 673-689.

[28] Ma C, Chang J, Lin D. Input force estimation of beam structure by an inverse method. Journal of Sound and Vibration. 2003, 259(2): 387 407.

[29] Schandl G, Lungner P, Benatzky C, Kozek M and Stribersky A Comfort enhancement by an active vibration reduction system for a flexible railway car body. Vehicle System Dynamics, 2007, 45(9):835847.

[30] Zhou J, Googall R, Ren L and Zhang H. Influences of car body vertical flexibility on ride quality of passenger railway vehicles. Proceedings of the Institution of Mechanical Engineers, Part F. Journal of rail and rapid transit,2009,5(5):461-471. 